\title{
A simplified method for monitoring respiratory impedance during continuous positive airway pressure
}

\author{
D. Navajas*, C. Duvivier**, R. Farré*, R. Peslin**
}

\begin{abstract}
A simplified method for monitoring respiratory impedance during continuous positive airway pressure. D. Navajas, C. Duvivier, R. Farré, R. Peslin. (C)ERS Journals Ltd 2000. ABSTRACT: The forced oscillation technique is useful in detecting changes in upper airway obstruction in patients with sleep apnoea undergoing continuous positive airway pressure (CPAP) ventilation. The aim of this study was to implement and evaluate a method for estimating respiratory impedance (Zrs) from the pressure and flow recorded at the inlet of the CPAP tubing.

The method is based on correcting impedance measured at the inlet of the CPAP tubing $(Z i)$ for the effect of the tubing and the exhalation port. The method was evaluated in mechanical analogues and in a healthy subject. Sinusoidal oscillation of 5, 10 and $20 \mathrm{~Hz}$ were superimposed on CPAP $\left(5-15 \mathrm{cmH}_{2} \mathrm{O}\right)$.

At $5 \mathrm{~Hz}$, the changes in airflow obstruction were substantially underestimated by $Z i$. Furthermore, $Z i$ exhibited a negative dependence on $Z$ rs at $20 \mathrm{~Hz}$. The assessment of $Z$ rs was greatly improved after correcting $Z i$ for the effects of the CPAP tubing and the exhalation port. $Z$ rs was well estimated at low frequencies, reaching very high values during total occlusion $\left(>60 \mathrm{cmH}_{2} \mathrm{O} \cdot \mathrm{s} \cdot \mathrm{L}^{-1}\right.$ at $\left.5-10 \mathrm{~Hz}\right)$.

These results indicate that changes in airflow obstruction can be detected using the forced oscillation technique from pressure and flow recorded on the continuous positive airway pressure device. This facilitates the clinical application of the forced oscillation technique for monitoring upper airway patency during sleep.

Eur Respir J 2000; 15: 185-191.
\end{abstract}

\author{
*Laboratorio Biofisica i Bioenginyeria, \\ Facultat Medicina, Universitat Barcelona, \\ Institut d'Investigacions Biomèdiques Au- \\ gust Pi i Sunyer, Barcelona, Spain **Unité 14 \\ de Physiopathologie Respiratoire, Institut \\ National de la Santé et de la Recherche \\ Medical, Nancy, France \\ Correspondence: D. Navajas Laboratorio \\ Biofisica i Bioenginyeria Facultat Medi- \\ cina Casanova 143 08036-Barcelona Spain \\ Fax: 34934024516 \\ Keywords: Airflow obstruction \\ airway occlusion \\ forced oscillation \\ respiratory resistance \\ sleep apnoea \\ Received: October 201998 \\ Accepted after revision November 71999 \\ This work was supported, in part, by the \\ Comisión Interministerial de Ciencia y Tec- \\ nologá(SAF99-0001 andPM980027). D.Nav- \\ ajas was a visiting professor at the INSERM, \\ Unité 14.
}

The forced oscillation technique (FOT) is a noninvasive approach for measuring respiratory impedance (Zrs) [1-4]. The technique is based on applying low-amplitude pressure oscillation to the airway opening and computing $\mathrm{Zrs}$ as the complex ratio between oscillatory pressure and flow. During sleep, the oscillation is applied to the nose of the patient by means of a nasal mask and $Z$ rs is computed from the pressure and flow recorded at the entrance to the nasal mask. It has been recently demonstrated that $Z_{\mathrm{rs}}$ measured by means of the FOT is a sensitive index for assessing airway obstruction during sleep apnoea both for diagnosis [5] and during continuous positive airway pressure (CPAP) treatment $[6,7]$. Moreover, $Z$ rs can be readily computed in real time, providing a continuous index of airway obstruction, which can be included on-line in polysomnographic recordings [8]. Furthermore, the pressure oscillation can be generated by the CPAP device, obviating the need for using an external forced oscillation generator $[9,10]$. Therefore, the FOT seems very well suited to monitoring airway patency and for automatic CPAP titration.

Nasal pressure and flow can be measured in the sleep laboratory by placing a pneumotachograph and a pressure transducer at the entrance to the nasal mask. However, this procedure hinders the use of the FOT in sleep studies and CPAP treatments in the patient's home. Thus. the aim of this study was to implement and evaluate a method for esti- mating $Z$ rs from pressure and flow recorded at the inlet of the CPAP tubing. The method is based on correcting the impedance measured at the inlet of the CPAP tubing $(Z i)$ for the effect of the tubing and the exhalation port. First, the CPAP tubing was characterized as a linear T-network circuit and the exhalation port as a pressure-dependent impedance. Subsequently the method was evaluated by connecting a conventional CPAP system to mechanical analogues featuring different degrees of airflow obstruction. Finally, the suitability of the method for detecting sudden changes in airway patency in a healthy subject performing voluntary upper airway occlusion manoeuvres was tested.

\section{Methods}

\section{Experimental set-up}

CPAP was generated via a conventional device (REM+; Société NellcorPuritan-Bennett. Nancy, France) attached to flexible tubing of $2.0 \mathrm{~cm}$ internal diameter (ID) and $180 \mathrm{~cm}$ in length (fig. 1). Forced oscillation was superimposed on the CPAP by means of a loudspeaker $(600 \mathrm{~W}$. $800 \mathrm{GTI}$; JBL, Northridge, CA, USA) connected to the inlet of the hose. The rear part of the loudspeaker was enclosed in a 5-L chamber so as to withstand the continuous positive pressure of the circuit [11]. Indeed, because of the low 


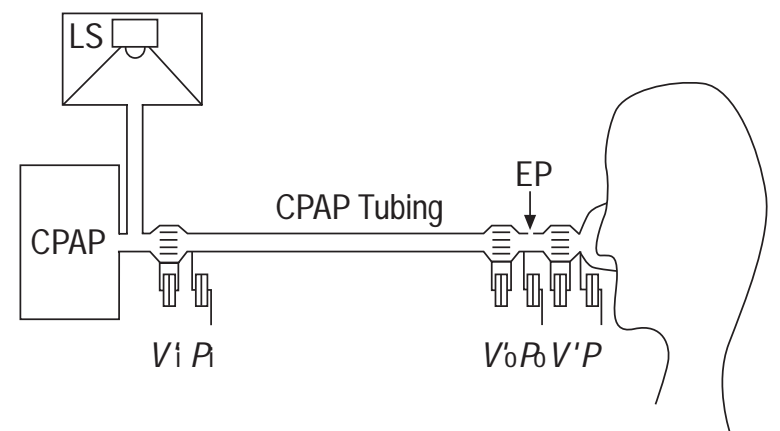

Fig. 1. - Schematic diagram of the experimental set-up. LS: loudspeaker; EP: exhalation port; CPAP: continuous positive airway pressure; $V^{\prime}$ i, $V_{0}^{\prime}$ and $V^{\prime}$ : flow at the inlet and outlet of the CPAP tubing and at the entrance of the nasal mask; $P \mathrm{i}, P_{\mathrm{o}}$ and $P$ : pressure at the inlet and outlet of the CPAP tubing and at the entrance of the nasal mask.

compliance of the gas in the chamber $\left(\sim 5 \mathrm{~mL} \cdot \mathrm{cmH}_{2} \mathrm{O}^{-1}\right)$ the maximum CPAP applied $\left(15 \mathrm{cmH}_{2} \mathrm{O}\right)$ displaced the loud-speaker cone by only $\sim 3 \mathrm{~mm}$, which kept the cone within its operating range. The outlet of the CPAP tubing was connected to an exhalation port, which was constructed by drilling an orifice of $4 \mathrm{~mm}$ in diameter in the wall of a rigid tube of $2.5 \mathrm{~cm}$ ID and $7 \mathrm{~cm}$ in length. This orifice had a well-defined pressure/flow relationship with nonlinear resistance similar to that of other commonly used exhalation ports. The outlet of the CPAP system was attached to a nasal mask. For measurements in the mechanical analogues, the nasal mask was removed and the outlet of the CPAP system connected to the analogue by means of a short piece of tubing of $2 \mathrm{~cm}$ ID. Flow at the inlet $\left(V^{\prime}\right.$ i) and outlet $\left(V^{\prime}\right)$ of the CPAP tubing and at the entrance of the nasal mask $\left(V^{\prime}\right)$ were measured with Fleisch No. 2 pneumotachographs (Métabo, Epalinges, Switzerland) connected to differential piezoresistive transducers $\left( \pm 35 \mathrm{cmH}_{2} \mathrm{O}, 176 \mathrm{PC} / 14\right.$; Honeywell, Freeport, IL, USA). Similar transducers were used for measuring pressure at the inlet $\left(P_{\mathrm{i}}\right)$ and outlet $\left(P_{\mathrm{o}}\right)$ of the CPAP tubing and at the entrance of the nasal mask $(P)$. The common mode rejection ratios (CMRRs) of the flow transducers were $>60 \mathrm{~dB}$ at $32 \mathrm{~Hz}$ [12]. The flow and pressure-measuring systems were matched in amplitude $( \pm 2 \%)$ and phase $\left( \pm 2^{\circ}\right)$ up to $32 \mathrm{~Hz}$.

\section{Respiratory impedance estimation}

Zrs was estimated from $Z \mathrm{i}$ by correcting it for the effect of both the CPAP tubing and the exhalation port. The CPAP tubing can be considered as a passive two-port system. Assuming linearity and taking into account the symmetry of the tubing, the two-port system is equivalent to a T-network circuit [13] with a shunt impedance ( $Z$ sh) between two identical series impedances ( $Z \mathrm{~s}$ ) (fig. 2). Solving the impedance network for $P \mathrm{i}$ and $P \mathrm{o}$, the oscillatory pressure/flow relationships can be expressed as [13]:

$$
\begin{gathered}
P_{\mathrm{i}}=\left(Z_{\mathrm{sh}}+Z_{\mathrm{s}}\right) V_{\mathrm{i}}^{\prime}-Z_{\mathrm{sh}} \times V_{\mathrm{o}}^{\prime} \\
P_{\mathrm{o}}=Z_{\mathrm{sh}} \times V_{\mathrm{i}}^{\prime}-\left(Z_{\mathrm{sh}}+Z_{\mathrm{s}}\right) \times \times V_{\mathrm{o}}^{\prime}
\end{gathered}
$$

The pressures are defined relative to atmospheric pressure. Dividing Equations 1 and 2 by $V^{\prime} \mathrm{i}$ and $V^{\prime} \mathrm{o}$

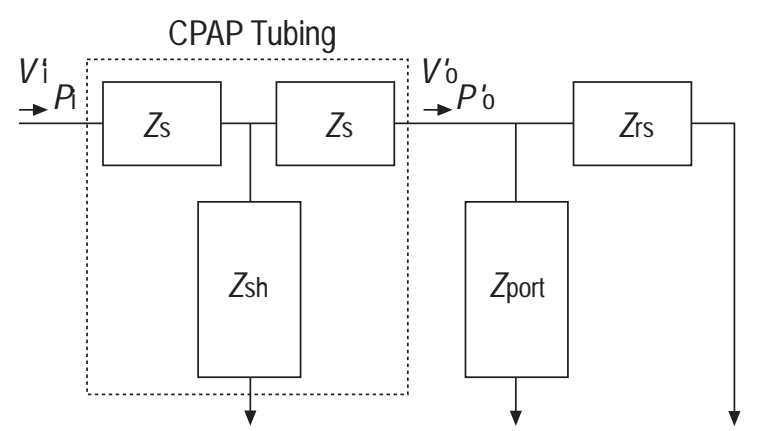

Fig. 2. - Equivalent circuit to the experimental set-up of the continuous positive airway pressure system (CPAP) system. Zs and Zsh: series and shunt impedances of the T-network model of the CPAP tubing; Zport: impedance of the exhalation port; $Z$ rs: respiratory impedance; $V^{\prime} \mathrm{i}$ and $V$ o: flow at the inlet and outlet of the CPAP tubing; $P$ i and $P$ o: pressure at the inlet and outlet of the CPAP tubing.

respectively, they may be rewritten as:

$$
\begin{aligned}
Z_{\mathrm{sh}} & \left.=\left(Z_{\mathrm{i}}+Z_{\mathrm{o}}\right) /\left(\left(V_{\mathrm{i}}^{\prime} / V^{\prime} i\right)\right)-\left(V_{o}^{\prime} / V_{i}^{\prime}\right)\right) \\
Z_{\mathrm{s}} & =Z_{\mathrm{i}} /\left(1+V_{\mathrm{o}}^{\prime} / V_{\mathrm{i}}^{\prime}\right)-\left(1+V_{\mathrm{i}}^{\prime} / V_{\mathrm{o}}^{\prime}\right),
\end{aligned}
$$

where $Z_{\mathrm{i}}=P_{\mathrm{i}} / \mathrm{V}^{\prime} \mathrm{i}$ and $Z_{\mathrm{o}}=P_{\mathrm{o}} / \mathrm{V}^{\prime} \mathrm{o}$, are the impedances measured at the inlet and outlet of the CPAP tubing, respectively. The value of $Z$ s and $Z$ sh can be determined from these equations by measuring $Z \mathrm{i}, Z_{\mathrm{o}}$ and $\mathrm{V}^{\prime} \mathrm{i} / \mathrm{V}^{\prime} \mathrm{o}$ with the system connected to an arbitrary load impedance.

Solving Equations 3 and 4 for $Z_{0}$

$$
Z_{\mathrm{o}}=\left(Z_{\mathrm{sh}^{2}} /\left(Z_{\mathrm{s}}+Z_{\mathrm{s}}-Z_{\mathrm{i}}\right)\right)-Z_{\mathrm{sh}}-Z_{\mathrm{s}}
$$

The exhalation port can be characterized as a nonlinear impedance (Zport) connected in parallel to $Z$ sh (fig. 2). Hence,

$$
Z_{\text {rs }}=Z_{\mathrm{o}} \times Z_{\text {port }} / Z_{\text {port }}-Z_{\mathrm{o}}
$$

Therefore provided that the T-network impedances of the CPAP tubing and the $Z$ port are known $Z$ rs can be estimated from the pressure and flow measured in the CPAP device.

\section{Experimental protocol}

First, the CPAP tubing and the exhalation port were characterized. The static elastance of the CPAP tubing (gas and walls) was measured by occluding its extremities and injecting $10 \mathrm{~mL}$ of air using a syringe. The T-network impedances were determined by connecting the outlet of the CPAP system to a resistor of $11 \mathrm{cmH}_{2} \mathrm{O} \cdot \mathrm{s} \cdot \mathrm{L}^{-1}$ built with 10 layers of $25-\mu \mathrm{m}$ mesh wire screen. Low amplitude $( \pm 1$ $\mathrm{cmH}_{2} \mathrm{O}$ ) pressure oscillations of 5,10 and $20 \mathrm{~Hz}$ were sequentially superimposed on a CPAP level of $10 \mathrm{cmH}_{2} \mathrm{O}$. $Z$ sh and $Z$ s were computed (Equations 3 and 4) from $16 \mathrm{~s}$ of pressure and flow recorded at the input $\left(P_{\mathrm{i}}, V^{\prime} \mathrm{i}\right)$ and output $\left(P_{\mathrm{o}}, V_{\mathrm{o}}\right)$ of the CPAP tubing. Since $P_{\mathrm{o}}$ was measured beyond the pneumotachograph placed at the outlet of the CPAP tubing, the values of the ratio $P_{\mathrm{o}} / V_{\mathrm{o}}^{\prime}$ (Equations 3 and 4) were corrected for the impedance of the pneumotachograph. The Zport was measured by occluding the outlet of the CPAP system and sequentially applying sinusoidal oscillations of 5,10 and $20 \mathrm{~Hz}$ at CPAP levels of $0,5,10$ and $15 \mathrm{cmH}_{2} \mathrm{O}$. In these experiments, the flow was measured with the $V^{\prime}$ pneumotachograph attached to the 


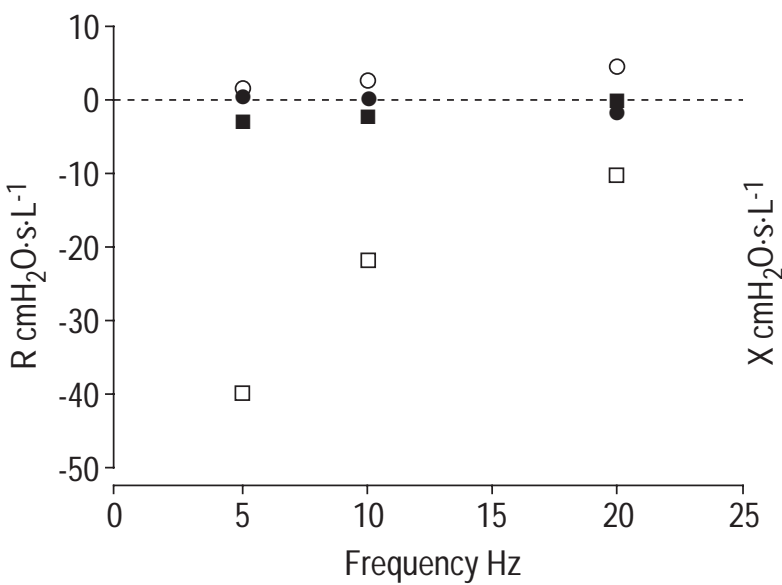

Fig. 3. - Frequency dependence of the T-network elements. $\bigcirc, \bullet$ : series impedance; $\square$, $\mathbf{\square}$ : shunt impedance; $\bullet$, $\mathbf{\square}$ : resistance $(R) ; O, \square$ : reactance $(X)$.

lateral port in order to accurately measure the flow through the orifice by avoiding gas compression effects. The pressure/flow relationship of the exhalation port was also measured under constant flow conditions (without oscillation) by continuously increasing the CPAP level from 0 to $20 \mathrm{cmH}_{2} \mathrm{O}$.

The correction method was first evaluated by occluding the outlet of the CPAP system. Next, the CPAP system was connected to three resistors ( $\mathrm{R} 1, \mathrm{R} 2$ and $\mathrm{R} 3$ ) ranging $\sim 5-$ $20 \mathrm{cmH}_{2} \mathrm{O} \cdot \mathrm{s} \cdot \mathrm{L}^{-1}$. The lower resistors $\left(\mathrm{R} 15.5 \mathrm{cmH}_{2} \mathrm{O} \cdot \mathrm{s} \cdot \mathrm{L}^{-1}\right.$; $\mathrm{R} 211 \mathrm{cmH} \mathrm{C}_{2} \mathrm{O} \cdot \mathrm{s} \cdot \mathrm{L}^{-1}$ ) were made with several layers of $25-\mu$ mesh wire screen. The higher resistor $\left(\mathrm{R} 322 \mathrm{cmH}_{2} \mathrm{O} \cdot \mathrm{s} \cdot \mathrm{L}^{-1}\right)$ was made with a hollow cylinder of porous ceramic. Since the CPAP blower could not achieve $15 \mathrm{cmH}_{2} \mathrm{O}$ when connected to R1 and R2 the outlet of these resistors were attached to a plastic container with an elastance of 20 $\mathrm{cmH}_{2} \mathrm{O} \cdot \mathrm{L}^{-1}$. Finally the method was tested during voluntary manoeuvres of upper airway occlusion performed by an awake healthy subject. In these measurements, R1 was placed between the pneumotachograph $\left(V^{\prime}\right)$ and the nasal mask in order to achieve nasal impedance values similar to those reported in healthy subjects during sleep $[14,15]$. In each of the above experimental conditions, $16 \mathrm{~s}$ of low amplitude $\left(+1 \mathrm{cmH}_{2} \mathrm{O}\right)$ pressure oscillations of 5, 10 and $20 \mathrm{~Hz}$ at CPAP levels of 5, 10 and $15 \mathrm{cmH}_{2} \mathrm{O}$ were applied.

\section{Data processing}

The pressure and flow recordings were digitized at a rate of 16 points per oscillation cycle $(80,160$ and $320 \mathrm{~Hz})$ using a microcomputer (12-bit AD/DA board; 486-type personal computer). The real (resistance $(R)$ ) and imaginary (reactance; $(X))$ parts of the sinusoidal components of the pressure and flow recordings were computed on a cycle by cycle basis from the Fourier coefficients at the forcing frequency [11]. Impedances were computed as the complex ratio between the corresponding pressure and flow recordings. Impedance data were digitally corrected for the time constant of the pneumotachograph. Zrs was estimated $\left(Z_{\mathrm{rs}}{ }^{*}\right)$ by correcting $Z_{\mathrm{i}}$ for the effects of the Tnetwork and exhalation port according to Equations 5 and

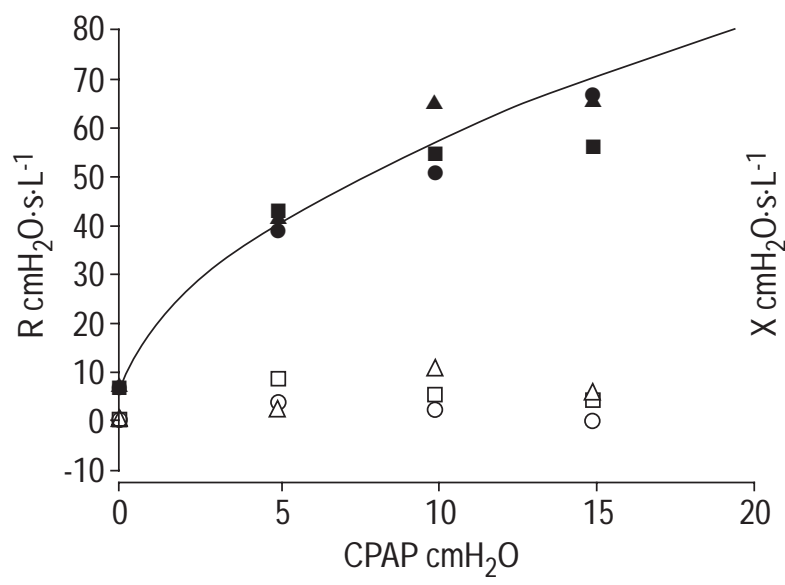

Fig. 4. - Continuous positive airway pressure (CPAP) dependence of oscillatory resistance $(R ; \bullet, \mathbf{\Delta}, \mathbf{\square})$ and reactance $(X ; \bigcirc, \triangle, \square)$ of the exhalation port at different frequencies. $\bigcirc, \bullet: 5 \mathrm{~Hz} ; \square, \boldsymbol{\square}: 10 \mathrm{~Hz} ; \triangle, \mathbf{\Delta}$ : $20 \mathrm{~Hz} . \longrightarrow$ : constant flow resistance.

6. $Z \mathrm{i}, Z_{\mathrm{rs}}$ and $Z \mathrm{rs}$ * are reported as their modulus computed as $\left(R^{2}+X^{2}\right)^{0.5}$. The impedance results obtained in the mechanical analogues are given as their mean values over the $16 \mathrm{~s}$ of forced oscillation.

\section{Results}

The CPAP tubing had a static elastance of 1,146 $\mathrm{cmH}_{2} \mathrm{O} \cdot \mathrm{L}^{-1}$. The T-network impedances are shown in figure 3 . The $Z$ sh was mostly elastic with a negative shunt reactance $(X \mathrm{sh})$ which rose inversely with frequency from $-40.0 \mathrm{cmH}_{2} \mathrm{O} \cdot \mathrm{s} \cdot \mathrm{L}^{-1}$ at $5 \mathrm{~Hz}$ to $-9.9 \mathrm{cmH}_{2} \mathrm{O} \cdot \mathrm{s} \cdot \mathrm{L}^{-1}$ at $20 \mathrm{~Hz}$. Nevertheless, $Z$ sh exhibited a small negative shunt resistance $(R \mathrm{sh})$, which increased slightly with frequency approaching zero at $20 \mathrm{~Hz}$. Conversely, the $Z$ s showed an inertive behaviour with a positive series reactance $\left(X_{\mathrm{s}}\right)$ which increased linearly with frequency reaching 4.5 $\mathrm{cmH}_{2} \mathrm{O} \cdot \mathrm{s} \cdot \mathrm{L}^{-1}$ at $20 \mathrm{~Hz}$. The series resistance $(R \mathrm{~s})$ was small and positive at low frequencies, becoming slightly negative at $20 \mathrm{~Hz}$.

The exhalation port exhibited marked nonlinear resistance under both constant and oscillatory flows (fig. 4). The pressure/flow relationship measured at constant flow showed quadratic flow dependence $\left(P=K V^{2}\right.$ where $\mathrm{K}$ is a constant $\left.82 \mathrm{cmH}_{2} \mathrm{O} \cdot \mathrm{s}^{2} \cdot \mathrm{L}^{-2}\right)$. Thus, constant flow resistance at the outlet of the CPAP tubing $\left(R_{0}\right)$ computed as $\mathrm{d} P / \mathrm{d} V^{\prime}$, increased linearly with flow $\left(R_{0}=2 K V^{\prime}\right)$ and linearly with the square root of pressure $\left(R_{0}=2 \mathrm{~K}^{0.5} \times \mathrm{P}^{0.5}\right)$. The real part of Zport (Rport) exhibited the same flow and pressure dependence as Ro. At a CPAP of $0 \mathrm{cmH}_{2} \mathrm{O}$, the port showed low resistance ( $R$ port $\sim 6 \mathrm{cmH}_{2} \mathrm{O} \cdot \mathrm{s} \cdot \mathrm{L}^{-1}$ ), but rose sharply to very high values when CPAP was applied. This marked CPAP dependence of Rport contrasts with the small changes observed when oscillatory frequency was varied. The reactance of $Z$ port (Xport) also showed little dependence on frequency. The exhalation port behaved as a pure resistance at CPAP of $0 \mathrm{cmH}_{2} \mathrm{O}(X$ port 0 $\left.\mathrm{cmH}_{2} \mathrm{O} \cdot \mathrm{s} \cdot \mathrm{L}^{-1}\right)$ but exhibited a slight positive reactance with CPAP.

The impedances of the mechanical analogues were greatly misestimated by $\mathrm{Zi}$ (fig. $5 \mathrm{a}$ ). At $5 \mathrm{~Hz}, \mathrm{Zi}$ slightly overestimated load impedance for $\mathrm{Zrs}<10 \mathrm{cmH}_{2} \mathrm{O} \cdot \mathrm{s} \cdot \mathrm{L}^{-1}$ 

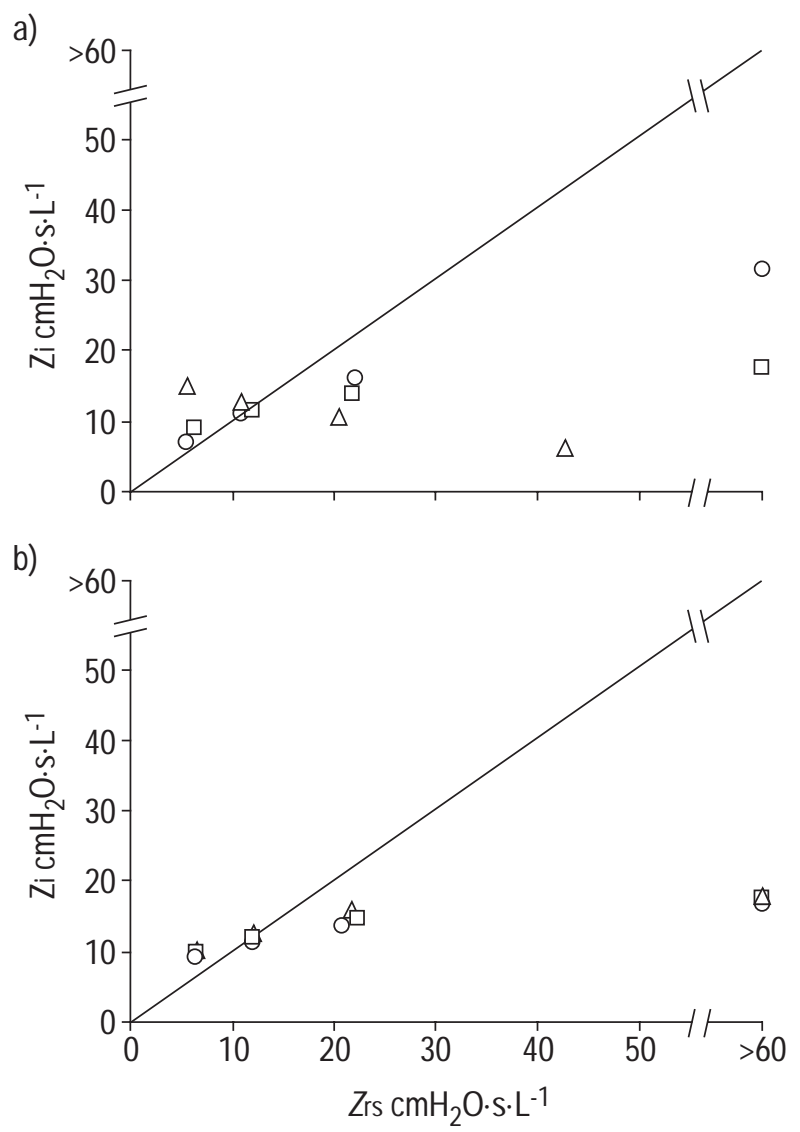

Fig. 5. - Frequency (a) and continuous positive airway pressure (CPAP) (b) dependence of the relationship between impedance measured at the inlet of the CPAP tubing $\left(Z_{i}\right)$ and the respiratory impedance of the analogues $(Z \mathrm{rs})$. Measurements were carried out at: a) $\mathrm{CPAP}=10 \mathrm{cmH}_{2} \mathrm{O}$ $(\bigcirc: 5 \mathrm{~Hz} ; \square: 10 \mathrm{~Hz} ; \triangle: 20 \mathrm{~Hz})$; and b) $10 \mathrm{~Hz}\left(\mathrm{O}: 5 \mathrm{cmH}_{2} \mathrm{O} ; \square: 10\right.$ $\left.\mathrm{cmH}_{2} \mathrm{O} ; \triangle: 15 \mathrm{cmH}_{2} \mathrm{O}\right)$.

and substantially underestimated it for higher loads, reaching $\sim 30 \mathrm{cmH}_{2} \mathrm{O} \cdot \mathrm{s} \cdot \mathrm{L}^{-1}$ during occlusion. Thus, although $Z \mathrm{i}$ rose with increasing load, the change in $Z \mathrm{i}$ between the lowest load and occlusion was limited to $\sim 25 \mathrm{cmH}_{2} \mathrm{O} \cdot \mathrm{s} \cdot \mathrm{L}^{-1}$. This over- and underestimation for low and high loads, respectively, was more marked at $10 \mathrm{~Hz}$, which further narrowed the range of $\mathrm{Zi}$ to $\sim 8 \mathrm{cmH}_{2} \mathrm{O} \cdot \mathrm{s} \cdot \mathrm{L}^{-1}$ (from 9 to 17 $\left.\mathrm{cmH}_{2} \mathrm{O} \cdot \mathrm{s} \cdot \mathrm{L}^{-1}\right)$. At $20 \mathrm{~Hz}$, the artefact was so important that $Z \mathrm{i}$ exhibited a negative dependence on $Z$ rs. In contrast, with the marked frequency dependence of the $Z \mathrm{i} / Z \mathrm{rs}$ relationship, it depended very little on CPAP (fig. 5b).

The assessment of $Z$ rs was greatly improved after correcting $Z_{i}$ for the effects of the CPAP tubing and the exhalation port. Figure 6 a depicts the accuracy of impedance estimates obtained at a CPAP of $10 \mathrm{cmH}_{2} \mathrm{O}$. Similar results were found at 5 and $15 \mathrm{cmH}_{2} \mathrm{O}$. Z rs was very well estimated at low frequencies. At $5-10 \mathrm{~Hz} Z \mathrm{rs} *$ attained very high values $\left(>60 \mathrm{cmH} \mathrm{C}_{2} \mathrm{O} \cdot \mathrm{s} \cdot \mathrm{L}^{-1}\right)$ during occlusion, which expanded the range of $\mathrm{Zrs}$ * variation, thereby improving substantially the detection of airflow obstruction. The correction procedure also improved $Z$ rs estimation at $20 \mathrm{~Hz}$, converting the paradoxical negative load dependence of $Z_{\mathrm{i}}$ into the positive linear dependence of $\mathrm{Zrs}_{\mathrm{r}}$. Nevertheless, some underestimation still remained at this high frequency after correcting $Z$ i for the effects of the CPAP tubing and the exhalation port. In order to ascertain
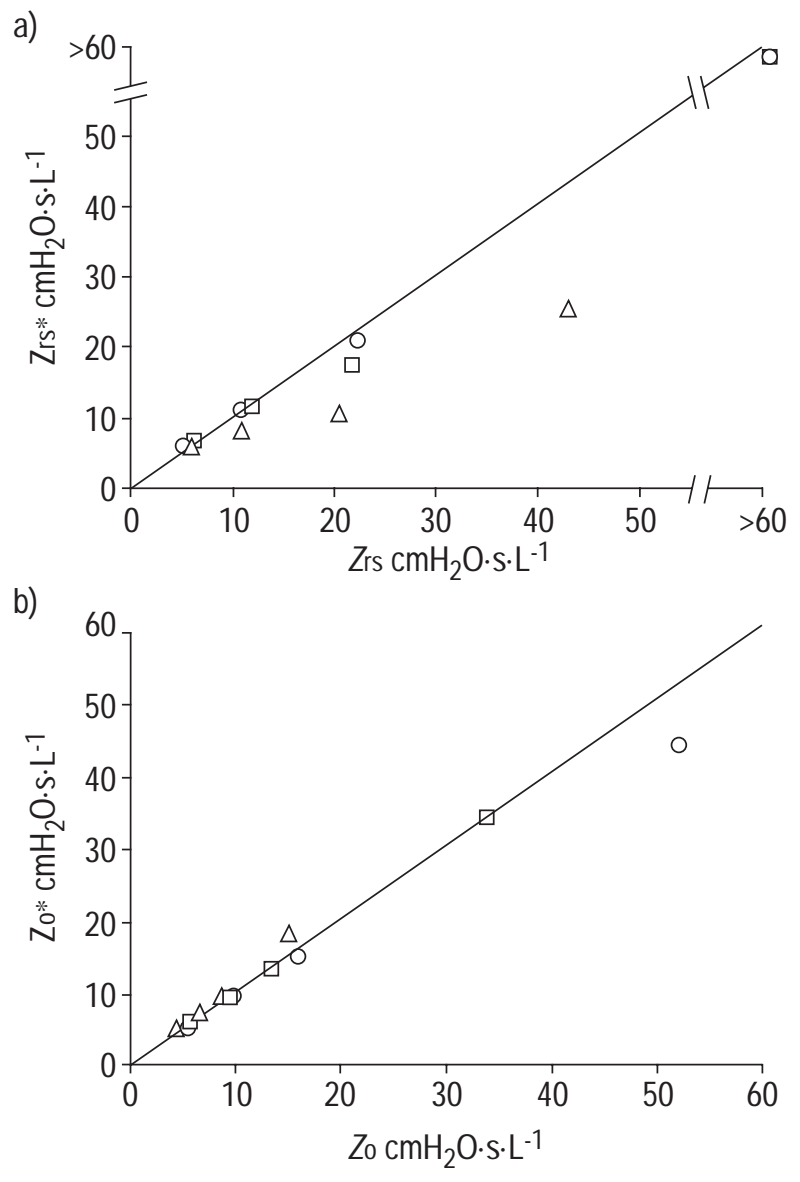

Fig. 6. - Relationship between: a) the impedance of the analogues $(Z \mathrm{rs})$ and that estimated $\left(Z_{\mathrm{rs}} *\right)$ from the pressure and flow recorded at the inlet of the continuous positive airway pressure (CPAP) tubing; and b) the impedance measured at the outlet of the CPAP tubing $\left(Z_{0}\right)$ and that estimated $\left(Z_{0} *\right)$ from the pressure and flow recorded at the inlet of the CPAP tubing. $\mathrm{CPAP}=10 \mathrm{cmH}_{2} \mathrm{O} . \bigcirc: 5 \mathrm{~Hz} ; \square: 10 \mathrm{~Hz} ; \triangle: 20 \mathrm{~Hz}$.

which of these two factors caused this underestimation. (Fig. 6b) the measured Zo were compared with those estimated from Equation $5\left(Z_{0}^{*}\right)$. Accurate estimation of Zo was found for all frequencies and pressures, indicating that the CPAP tubing behaved linearly and that the T-network correction performed very well. Thus, the underestimation of $Z$ rs at high frequencies should be attributed to the correction of $Z$ o for $Z$ port (Equation 6).

The $Z$ port estimated from the $Z$ rs and the $Z_{0}$ (Equation 6) during occlusion at $10 \mathrm{cmH}_{2} \mathrm{O}$ fell with increasing frequency from $48.2 \mathrm{cmH}_{2} \mathrm{O} \cdot \mathrm{s} \cdot \mathrm{L}^{-1}$ at $5 \mathrm{~Hz}$ to $11.4 \mathrm{cmH}_{2} \mathrm{O} \cdot \mathrm{s} \cdot \mathrm{L}^{-1}$ at $20 \mathrm{~Hz}$. This marked negative frequency dependence contrasts with the small change observed when Zport was computed by measuring the flow through the orifice (fig. 4).

Figure 7 depicts the assessment of changes in $\mathrm{Zrs}$ during voluntary occlusion manoeuvres at a CPAP of 10 $\mathrm{cmH}_{2} \mathrm{O}$. Similar results were found at other CPAP levels. Airway occlusion resulted in a sharp increase in $\mathrm{Zrs}$, which magnitude decreased with increasing frequency. In agreement with the data shown in figure 6 , at low frequency $Z \mathrm{i}$ was similar to $\mathrm{Zrs}$ during breathing, but the high values reached by $Z$ rs during occlusion had only a modest effect on $Z \mathrm{i}$. The assessment of $Z_{\text {rs }}$ via $Z \mathrm{i}$ worsened with increasing frequency. Occlusion produced 
a)

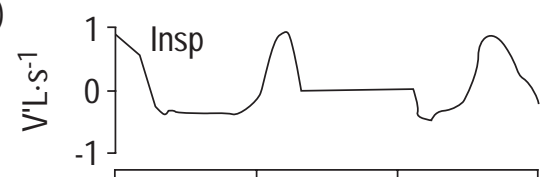

d)

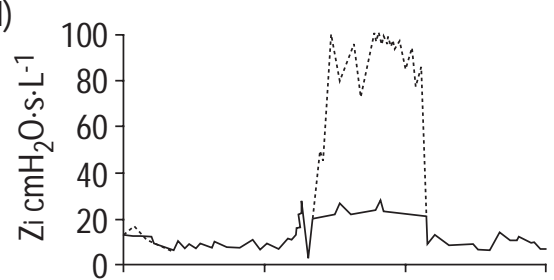

g)

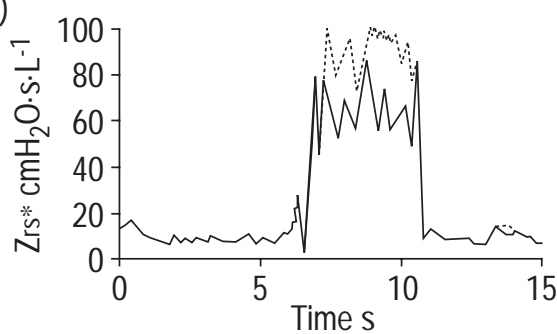

b)

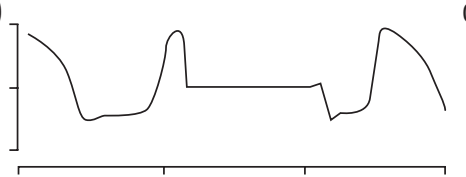

e)

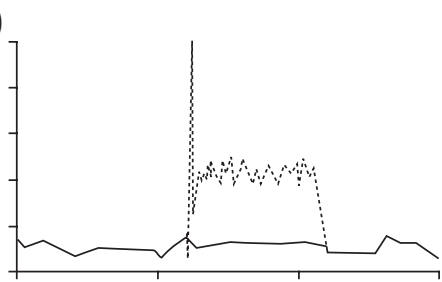

h)

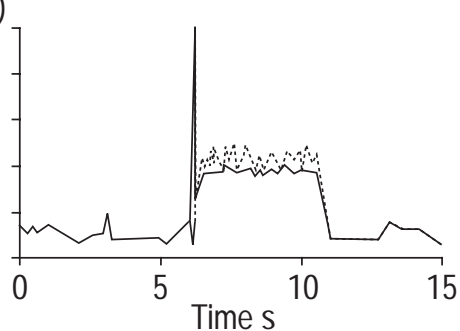

c)

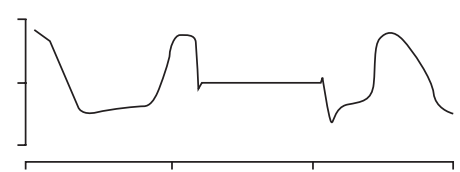

f)

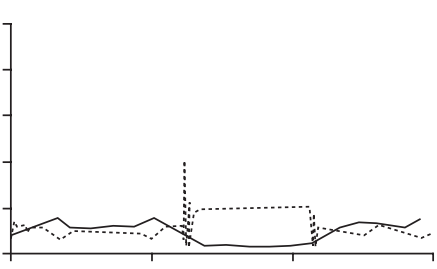

i)

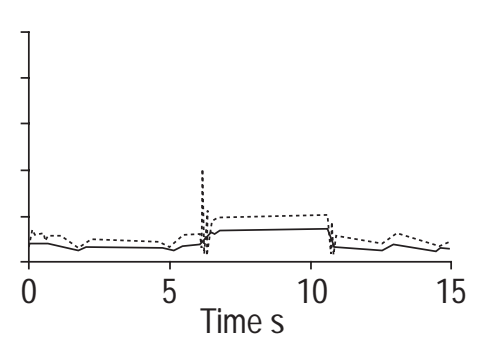

Fig. 7. - Nasal flow and impedance in a subject during voluntary upper airway occlusion at different frequencies. a, d, g) $5 \mathrm{~Hz}$; b, e, h) $10 \mathrm{~Hz}$; and c, f, i)

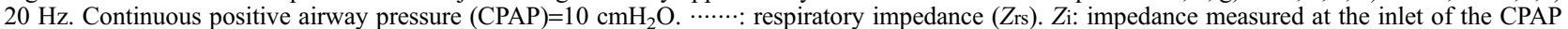
tubing; $Z_{\mathrm{rs}} *$ : estimated $Z_{\mathrm{rs}}$, by correcting $Z_{\mathrm{i}}$ for the effects of the T-network and the exhalation port; $V^{\prime}$ : flow at the entrance to the nasal mask; Insp: inspiration; Exp: expiration.

negligible changes in $Z \mathrm{i}$ at $10 \mathrm{~Hz}$ or even a fall in $\mathrm{Zi}$ at 20 $\mathrm{Hz}$. Correction of $Z \mathrm{i}$ for the effect of the CPAP tubing and exhalation port substantially improved airway ob-struction assessment. Indeed, $Z$ rs* attained high values during apnoea at low frequencies $(5-10 \mathrm{~Hz})$, allowing clear detection of airway occlusion. At higher frequency $\mathrm{Zrs}$ * exhibited a downward shift but the paradoxical behaviour of $\mathrm{Zi}$ was reversed and changes in $\mathrm{Zrs} *$ paralleled those in Zrs.

\section{Discussion}

Zrs can be readily measured during sleep by applying forced oscillation to the nose via CPAP tubing connected to the nasal mask. Long and flexible tubing is used in order to minimize sleep disturbance and to improve the patient's compliance. Nasal pressure and flow can be accurately recorded using pneumotachographs and pressure transducers placed at the entrance to the nasal mask. Although the location of these transducers at the entrance to the mask is not a significant drawback in the hospital sleep laboratory, it impedes the use of the FOT in the patient's home. This study showed that $Z$ rs can be reliably estimated at low frequencies from the pressure and flow recorded at the inlet of the CPAP tubing by correcting for the effect of the tubing and the exhalation port, characterized as a linear Tnetwork circuit and by a pressure-dependent impedance, respectively.

The simplest approach to estimating $Z_{\text {rs }}$ from the pressure and flow recorded at the inlet of the CPAP tubing is to assume that the effect of the tubing and the exhalation port is negligible and, thus, that $Z \mathrm{rs} \sim \mathrm{Zi}$. In contrast to this assumption, substantial discrepancies between $Z_{r s}$ and $Z_{i}$ were found when using a conventional tubing ( $2 \mathrm{~cm}$ ID, $180 \mathrm{~cm}$ in length) and an exhalation port (pressure-depen- dent resistance). At the lowest frequency $(5 \mathrm{~Hz}), \mathrm{Zi}$ exhibited a narrow range of variation between normal airflow resistance and total occlusion (figs. 5 and 7), which limits its sensitivity for detecting changes in airway patency. The effect of the tubing and the port increased with frequency, resulting in a paradoxical inverse relationship between $Z \mathrm{i}$ and $Z$ rs at $20 \mathrm{~Hz}$. Yen et al. [10] have recently suggested that $Z$ rs be estimated using the ratio $P /$ $V^{\prime} \mathrm{i}$, assuming that $V^{\prime} \sim V^{\prime}$ i. However, measuring pressure in the nasal mask, instead of in the CPAP device, does not appear to improve $Z$ rs estimation since dramatic differences were found between $V^{\prime}$ and $V^{\prime}$ i at high load. In particular, during occlusion at $5 \mathrm{~Hz}$, the amplitude of $V^{\prime} \mathrm{i}$ was $\sim 10$ times higher than that of $V^{\prime}$ and, thus, $P / V^{\prime}$ i overestimated $Z$ rs by the same factor. The present findings demonstrate, therefore, that the effects of the hose and the port must be taken into account, even with low frequency oscillation, in order to accurately estimate Zrs from pressure and flow recorded in the CPAP device. An alternative approach of measuring $Z$ rs without flow recording has been recently described [16]. The method uses a small mechanical pump to inject $20 \mathrm{~Hz}$ oscillatory flow at the inlet of the nasal mask. $Z$ rs is estimated from the pressure recorded at the nasal mask assuming that the impedance of the CPAP tubing is very high compared with $Z$ rs. In contrast to this hypothesis, the present data (fig. 3) show that the load impedance of CPAP tubing $(Z s+Z s h)$ can fall to $\sim 10 \mathrm{cmH}_{2} \mathrm{O}$ at $20 \mathrm{~Hz}$. which is comparable to the $Z \mathrm{rs}$ reported at similar frequencies $(16 \mathrm{~Hz})$ in patients with obstructive sleep apnoea syndrome [7].

The CPAP tubing was characterized as a symmetrical Tnetwork circuit. Given that the wave propagation equations for cylindrical rigid wall tubes $[17,18]$ are not applicable to a flexible hose. Its T-network impedances were empirically determined by connecting the system to a reference 
load. The tubing was loaded with a mid-range resistor (11 $\left.\mathrm{cmH}_{2} \mathrm{O} \cdot \mathrm{s} \cdot \mathrm{L}^{-1}\right)$ in order to improve the signal to noise ratio of this calibration. The close agreement found between $Z_{\mathrm{o}}^{*}$ and $Z_{\mathrm{o}}$ (fig. $6 \mathrm{~b}$ ) at a wide range of pressures (5-15 $\mathrm{cmH}_{2} \mathrm{O}$ ) demonstrated the suitability of the T-network for modelling conventional CPAP tubing subjected to 5-20 $\mathrm{Hz}$ oscillations. The serial element of the T-network (fig. 2) mainly reflected the inertance of the gas inside the tubing. Indeed, the effective inertance of the series elements. computed as $2 X \mathrm{~s} / \omega\left(0.072 \mathrm{cmH}_{2} \mathrm{O} \cdot \mathrm{s}^{2} \cdot \mathrm{L}^{-1}\right)$, agreed with the predicted gas inertance of the tubing $(0.075$ $\left.\mathrm{cmH}_{2} \mathrm{O} \cdot \mathrm{s}^{2} \cdot \mathrm{L}^{-1}\right)$. The shunt element exhibited elastic behaviour. The small negative $R$ sh found at low frequencies (fig. 2) could be an effect of the finite CMRR of flow transducers [12]. Shunt elastance $\left(-X \mathrm{~s} / \omega=1,250 \mathrm{cmH}_{2} \mathrm{O} \cdot \mathrm{L}^{-1}\right)$ was substantially lower than the gas elastance of the tubing $\left(2,560 \mathrm{cmH}_{2} \mathrm{O} \cdot \mathrm{L}^{-1}\right)$. However, shunt elastance compared well with the static elastance of the gas and the walls $\left(1,146 \mathrm{cmH}_{2} \mathrm{O} \cdot \mathrm{L}^{-1}\right)$. This demonstrates that wall properties cannot be neglected when considering the effect of the CPAP tubing on impedance measurements. The low total series impedance of the hose at $5 \mathrm{~Hz}$ and the close agreement between $Z$ sh and static elastance indicate that the method can be further simplified at low frequencies by neglecting $Z_{\mathrm{s}}$ and characterizing $Z_{\text {sh }}$ as the elastance of the gas and the walls. Such simplification resulted in an overestimation of $Z \mathrm{rs}$ i.e., $1 \mathrm{cmH}_{2} \mathrm{O} \cdot \mathrm{s} \cdot \mathrm{L}^{-1}$ at $5 \mathrm{~Hz}$, which could provide sufficient accuracy for several clinical applications.

The exhalation port is placed at the entrance to the nasal mask in order to generate a continuous flow to exhaust of $\mathrm{CO}_{2}$ from the patient circuit during CPAP treatment. Commonly used ports have nonlinear resistance, which reduces the CPAP dependence of the bias flow. In the present study, a 4-mm orifice was used and taken as representative of these nonlinear exhalation ports (fig. 4). Zport was determined by directly recording the pressure drop and the flow through the orifice. Zport was mainly resistive with good agreement between oscillatory and constant flow resistance (fig. 3). Zport was used to correct the impedance estimated at $5-10 \mathrm{~Hz}$ (fig. 6a), showing that the assumption regarding the parallel combination of Zport and $Z$ rs is reasonable at low oscillatory frequencies. However, Zrs was substantially underestimated at $20 \mathrm{~Hz}$, which indicates that the turbulent flow regimen induced by this nonlinear port caused a complex interaction between oscillation and bias flow. This resulted in an apparent reduction in Zport at high frequencies. Although this underestimation does not hinder the application of the method for qualitatively monitoring relative changes in $\mathrm{Zrs}$, the present findings suggest the use of a low oscillatory frequency when the pressure and flow are recorded at the inlet of the hose. Moreover, low frequency minimizes the effect of the upper airway, thus optimizing the sensitivity of the FOT in assessing airway patency [11].

The present method allows reliable estimation of changes in airflow obstruction using transducers placed by the CPAP device. In agreement with recommendations for the FOT [19], the method was assessed using wellcharacterized mechanical analogues and care taken to completely avoid leaks. At low frequencies, $Z \mathrm{rs} *$ increased linearly with $\mathrm{Zrs}$ and achieved values $>50-60 \mathrm{cmH}_{2} \mathrm{O} \cdot \mathrm{s} \cdot \mathrm{L}^{-1}$ during total occlusion. This can be taken as the practical limit for impedance measurements in sleep apnoea pati- ents. Indeed, $Z$ rs does not rise to higher values during total airway collapse because of the leaks through the nasal mask and the shunt of the upper airway wall $[5,6]$. Moreover, accurate measurements of higher impedances would require a better CMRR than that of the currently available transducers [12]. Therefore, $\mathrm{Zrs}$ * measured at $5-10 \mathrm{~Hz}$ could have a similar sensitivity to $Z \mathrm{rs}$ in monitoring airway obstruction during sleep apnoea. These low frequencies provide enough time resolution to detect sudden changes in upper airway patency and to track phasic variation in impedance during the breathing cycle [6].

The performance of the method was assessed during CPAP application with a long hose and a nonlinear exhalation port. These are the most difficult experimental conditions. A shorter hose would reduce the difference between $Z_{i}$ and $Z_{0}$. Using an exhalation port with linear resistance would simplify the correction and could improve the reliability of $Z$ rs estimation at high frequencies. Moreover, since the CPAP tubing exhibited linear behaviour, a linear resistance would allow multifrequency measurements to be carried out. The FOT has also been applied to the evaluation of sleep apnoea syndrome in patients breathing at atmospheric pressure [5]. In this case, the exhalation port is replaced by bias tubing acting as a pneumatic low-pass filter. Owing to the linear behaviour of this bias tubing, its input impedance can be easily calibrated and used in Equation 6 to compute $Z$ rs. Therefore, this method of correction can be applied to patients undergoing CPAP treatment as well as to patients breathing at atmospheric pressure. It should be noted however, that studies requiring high-frequency or very accurate measurement of $\mathrm{Zrs}$ may necessitate the location of the transducer within the nasal mask. The performance of the method was assessed by comparing the impedance estimated from the pressure and flow recorded at the inlet of the CPAP tubing with the value measured at the inlet of the mask. The method can, therefore, be used with any kind of nasal or facial mask. The calibration of the CPAP tubing and the exhalation port can be easily performed using additional flow and pressure transducers and a linear resistor, which can be precalibrated with the same set-up. Furthermore. since the behaviour of the tubing and the port is determined by their physical characteristics, calibration data can be used with any other unit of the same type.

In conclusion, the present findings suggest that airway obstruction can be reliably assessed using low-frequency forced oscillation $(5-10 \mathrm{~Hz})$ by estimating respiratory impedance from the pressure and flow recorded at the inlet of the continuous positive airway pressure tubing. This method could facilitate the use of the forced oscillation technique in the patient's home for monitoring upper airway patency during sleep and for automatic adjustment of the continuous positive airway pressure level.

\section{References}

1. Pride NB. Forced oscillation techniques for measuring mechanical properties of the respiratory system. Thorax 1992; 47: 317-320.

2. Zerall-Lancner F, Lofaso F, Coste A, Ricolfi F, Goldenberg F, Harf A. Pulmonary function in obese snorers with 
or without sleep apnoea syndrome. Am J Respir Crit Care Med 1997; 156: 522-527.

3. Ruhle KH, Schlenker E, Randerath W. Upper airway resistance syndrome. Respiration 1997; 64: 29-34.

4. Kita H, Ohi M, Chin K, et al. Effects of nasal continuous positive airway pressure therapy on respiratory parameters of upper airway patency in patients with obstructive sleep apnoea syndrome. Chest 1998; 114: 691-696.

5. Badia JR, Farré R, Montserrat JM, et al. Forced oscillation technique for the evaluation of the sleep apnoea hypopnea syndrome. A pilot study. Eur Respir J 1998; 11: 11281134.

6. Navajas D, Farré D, Rotger M, Badia R, Puig-de-Morales M, Montserrat JM. Assessment of airflow obstruction during CPAP by means of forced oscillation in patients with sleep apnoea. Am J Respir Crit Care Med 1998; 157: $1526-1530$.

7. Lorino AM, Lofaso F, Duizabo D, et al. Respiratory resistive impedance as an index of airway obstruction during nasal continuous positive airway titration. $\mathrm{Am} \mathrm{J}$ Respir Crit Care Med 1998; 158: 1465-1470.

8. Farré R, Rotger M, Montserrat JM, Navajas D. Analog circuit for real-time computation of respiratory mechanical impedance in sleep studies. IEEE Trans Biomed Eng 1997; 44: 1156-1159.

9. Farré R, Rotger M, Montserrat JM, Navajas D. A system to generate simultaneous forced oscillation and continuous positive airway pressure. Eur Respir J 1997; 10: 1349-1353.

10. Yen FC, Behbehani K, Lucas EA, Burk JR, Axe JR. A noninvasive technique for detecting obstructive and central sleep apnoea. IEEE Trans Biomed Eng 1997; 44: $1262-1268$.
11. Farré R, Peslin R, Rotger M, Navajas D. Inspiratory dynamic obstruction etected by forced oscillation during CPAP. A model study. Am J Respir Crit Care Med 1997; 155: 952-956.

12. Peslin R, Jardin P, Duvivier C, Begin P. In-phase rejection requirements for measuring respiratory input impedance. J Appl Physiol 1984; 56: 804-809.

13. Peslin R, Fredberg JJ. Oscillation mechanics of the respiratory system. In: Fishman AP, ed. Handbook of Physiology. Vol 3. Part 1. Bethesda, MD, American Physiological Society, 1988; pp. 153-154.

14. Henke KG, Dempsey JA, Badr MS, Kowitz JM, Skatrud JB. Effect of sleep-induced increases in upper airway resistance on respiratory muscle activity. $J$ Appl Physiol 1991; 70: 158-168.

15. Morrell MJ, Harty HR, Adams L, Guz A. Changes in total pulmonary resistance and $\mathrm{PCO} 2$ between wakefulness and sleep in normal human subjects. J Appl Physiol 1995; 78: 1339-1349.

16. Reisch S, Schneider M, Timmer J, Geiger K, Guttmann J. Evaluation of forced oscillation technique for early detection of airway obstruction in sleep apnoea: a model study. Technol Health Care 1998; 6: 245-257.

17. Benade $\mathrm{AH}$. On the propagation of sound waves in a cylindrical conduit. J Acoust Soc Am 1968; 44: 616-623.

18. Franken H, Clément J, Cauberghs M, van de Woestijne KP. Oscillating flow of a viscous compressible fluid through a rigid tube: a theoretical model. IEEE Trans Biomed Eng 1981; 28: 416-420.

19. van de Woestijne KP, Desager KN, Duiverinan EJ, Marchal F. Recommendations for measurement of respiratory input impedance by means of the forced oscillation method. Eur Respir Rev 1994; 4: 19, 235-237. 